\title{
Thymidine kinase 1: A proliferation marker for determining prognosis and monitoring the surgical outcome of primary bladder carcinoma patients
}

\author{
JIE ZHANG ${ }^{1}$, QUANAN JIA ${ }^{1}$, SHAN ZOU $^{1}$, PINGAN ZHANG $^{2}$, XIAOBING ZHANG ${ }^{1}$, SVEN SKOG $^{3}$, \\ PENGCHENG LUO ${ }^{1}$, WEI ZHANG ${ }^{1}$ and QIMIN HE ${ }^{3}$
}

Departments of ${ }^{1}$ Urology and ${ }^{2}$ Laboratory Science, RenMin Hospital of Wuhan University, Wuhan 430060, P.R. China;

${ }^{3}$ Department of Oncology Clinical Research Laboratory, Clinical Research Centre, Karolinska

University Hospital, Karolinska Institute, S-14186, Stockholm, Sweden

Received June 10, 2005; Accepted August 19, 2005

\begin{abstract}
Reliable markers for monitoring bladder tumor therapy are needed to evaluate treatment effectiveness. Thymidine kinase 1 (TK1) is an enzyme involved in DNA synthesis and therefore proliferation-dependent. Serum concentration of TK1 (STK1) correlates with malignancy in various types of cancer, thus reflecting treatment results. This study explores for the first time the use of STK1 concentration, both as a prognostic marker and to monitor the outcome of bladder carcinoma surgery. STK1 in 56 bladder carcinoma patients was measured pre-operatively, and postoperatively at 1 week and 1,3, and 6 months, using an immune ECL dot blot assay. An anti-TK1 chicken IgY antibody was used to determine STK1 concentrations. Mean pre-operative STK1 of bladder carcinoma patients was significantly higher than that of healthy individuals, with no overlap of individual values. STK1 concentrations increased significantly with tumor stage (I-III) and T-values (T1-T2), but not tumor grade (G1-G4). STK1 gradually declined, being $66 \%$ lower after 1 week. STK1 reached the level of healthy controls at 1 month and remained there for at least 6 months, post-operatively until this study ended. Since STK1 concentration correlates with tumor stage, degree of invasion and metastasis, and monitors the surgical outcome, it can be a reliable index to diagnose and determine prognosis in post-operative bladder carcinoma.
\end{abstract}

Correspondence to: Dr Qimin He, Department of Oncology Clinical Research Laboratory, Clinical Research Centre, Karolinska University Hospital (Huddinge), Karolinska Institute, S-14186 Stockholm, Sweden

E-mail: qimin.he@medhs.ki.se

Dr Jie Zhang, Department of Urology, RenMin Hospital of Wuhan University, Wuhan 430060, P.R. China

E-mail: zhangjie888@sina.com

Key words: bladder carcinoma, thymidine kinase 1, serum thymidine kinase 1, recurrence, anti-TK1 IgY chicken antibody

\section{Introduction}

Tumor markers are still not fully accepted in clinical use, although several have been used for decades. In bladder carcinoma, the use of biomarkers in detecting superficial disease or predicting the clinical outcome of individual tumors is limited and controversial. Carcinoembryonic antigens (CEA), CA125 and CA19.9 can be used to monitor patients with advanced malignancy $(1,2)$, while CEA CA50, and CA19 and tissue polypeptide antigen (TPA) have been used to distinguish surface from invasive tumors (3). TPA is a circulating complex of polypeptide fragments from cytokeratin 8, 18 and 19, which has been used for years. TPA levels are significantly higher in the serum and urine of patients with bladder cancer than in controls. However, no difference was found in the TPA levels between superficial and invasive bladder cancers (4). Cytokeratin 19 (CYFRA 21-1) might play a role in diagnosing bladder cancer and assist urologists in detecting bladder cancer as a non-invasive adjunct to cytoscopy (5). It might also be a useful marker in diagnosing transitional cell carcinoma as it is sensitive to low-grade disease (6). Tissue polypeptide-specific antigen (TPS) and polyclonal antibodies against cytokeratin 18 are also tumor markers for following up and establishing prognosis of bladder cancer. Serum TPS shows a correlation to stage, urine cytology, and tumor shape and size. There is a significant correlation between TPS and stage, presence of metastatic lymph nodes, metastasis, urinary cytology, and tumor shape and tumor size. However, grade, number of tumors, relapses, and recurrences were not significantly correlated with serum TPS, and do not appear to be useful in the follow-up of patients with bladder disease (7). It is clear that serum cytokeratin-18 level increases in patients with bladder cancer. However, cytokeratin-18 is only useful as a tumor marker in diagnosing T3 and higher stage tumors, but has no diagnostic value in lower stage bladder cancers (8). In evaluating the individual and combined use of three cytokeratin fragments, i.e. CYFRA 21-1, TPA, and TPS, in the serum of bladder cancer patients, the sensitivity of each of the three markers was found to increase with advancing tumor stage and grade. Combining 2 of the 3 markers did not 
Table I. Concentrations of STK1 in healthy persons and preoperative patients.

\begin{tabular}{lcc}
\hline & $\begin{array}{c}\text { Concentration } \\
\text { of STK1 }(\mathrm{pM})\end{array}$ & $\mathrm{p}$-value \\
\hline Healthy $(\mathrm{n}=20)$ & $1.2 \pm 0.6$ & $<0.001$ \\
Pre-operative STK1 $(\mathrm{n}=56)$ & $26.1 \pm 16.6$ & \\
Initial $(\mathrm{n}=38)$ & $21.5 \pm 7.5$ & \\
Recurrence $(\mathrm{n}=18)$ & $33.3 \pm 14.4$ & \\
$\begin{array}{l}\text { Superficial (n=12) } \\
\text { Invasive (n=33) }\end{array}$ & $15.4 \pm 4.5$ & \\
$\begin{array}{l}\text { The pre-operative patients were subdivided into four groups: initial } \\
\text { disease and recurrence, and superficial and invasive diseases. Mean } \\
\text { values } \pm \text { SD. p-values were calculated using the Student's t-test. }\end{array}$ \\
\hline
\end{tabular}

raise the sensitivity obtained by using CYFRA 21-1 alone (9). There are other serum markers, such as tumor-associated trypsine inhibitor (TATI) and MUC1. Serum TATI is an independent prognostic factor in transitional cell carcinoma and potentially useful for identifying patients with an adverse prognosis (10). MUC1 levels are high in advanced disease and serum MUC1 levels may be useful in monitoring disease, (11). It is suggested that high-throughput DNA micro-arrays will soon move from being technology restricted to research and clinical laboratories (12). Methylation of the p16 (INK4a) promoter may be a new type of tumor marker in bladder cancer (13).

New alternative markers are constantly being sought. Thymidine kinase 1 (TK1) was found to be a useful marker in tumor sections of breast (14-17), colorectal (18), lung (19), and prostate (20) cancer. The concentration of TK1 in serum (STK1), rather than its activity, was also found to be a useful marker in monitoring the outcome of tumor therapy in patients with breast (21), gastric (22), and lung (40) cancer. TK1 may also be used as a molecular therapeutic target (23). In primary bladder carcinomas, cytosolic TK activity in T1 tumors was twice that of Ta tumors. Cytosolic TK activity in

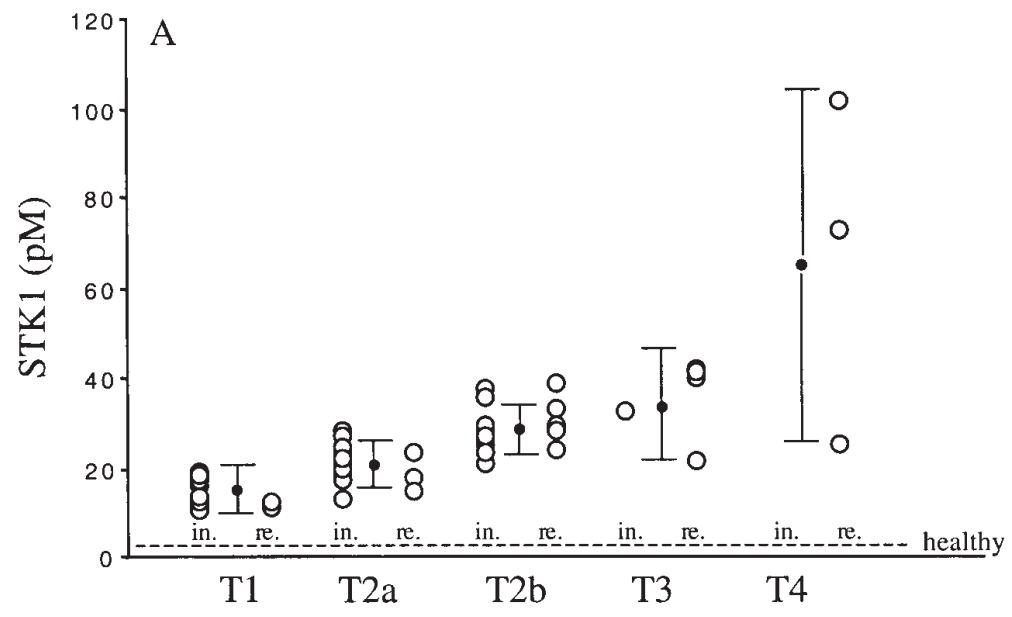

T-value

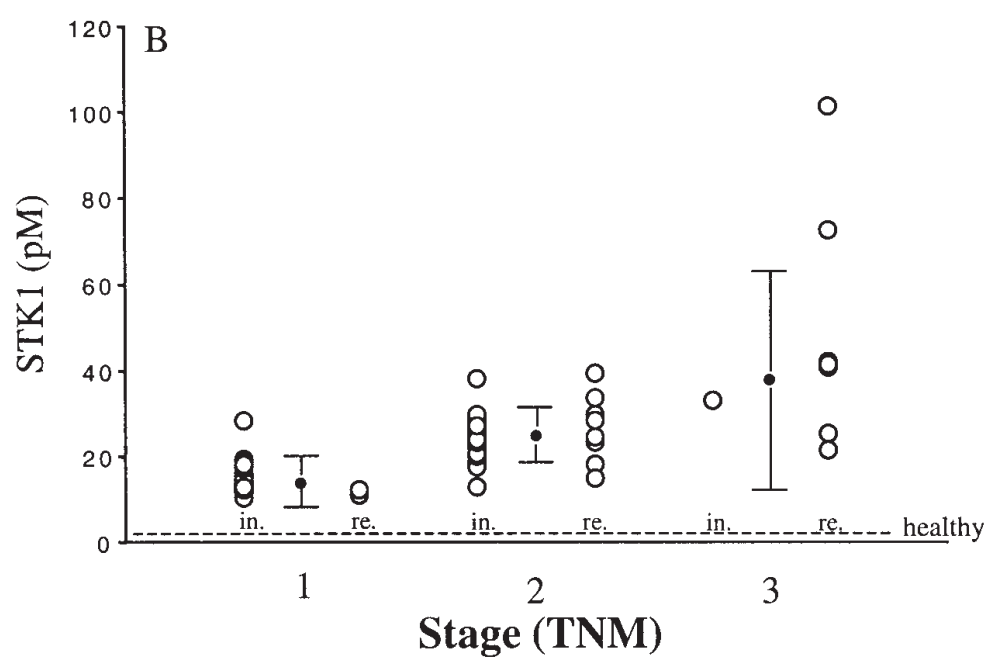

Figure 1. STK1 concentrations in relation to tumor T-value (A) and tumor stage (TNM) (B) for individual patients (open circle) and mean values (closed circle) are indicated. The mean \pm SD values were calculated from the initial and recurrence patients together. In, initial disease; re, recurrence. 


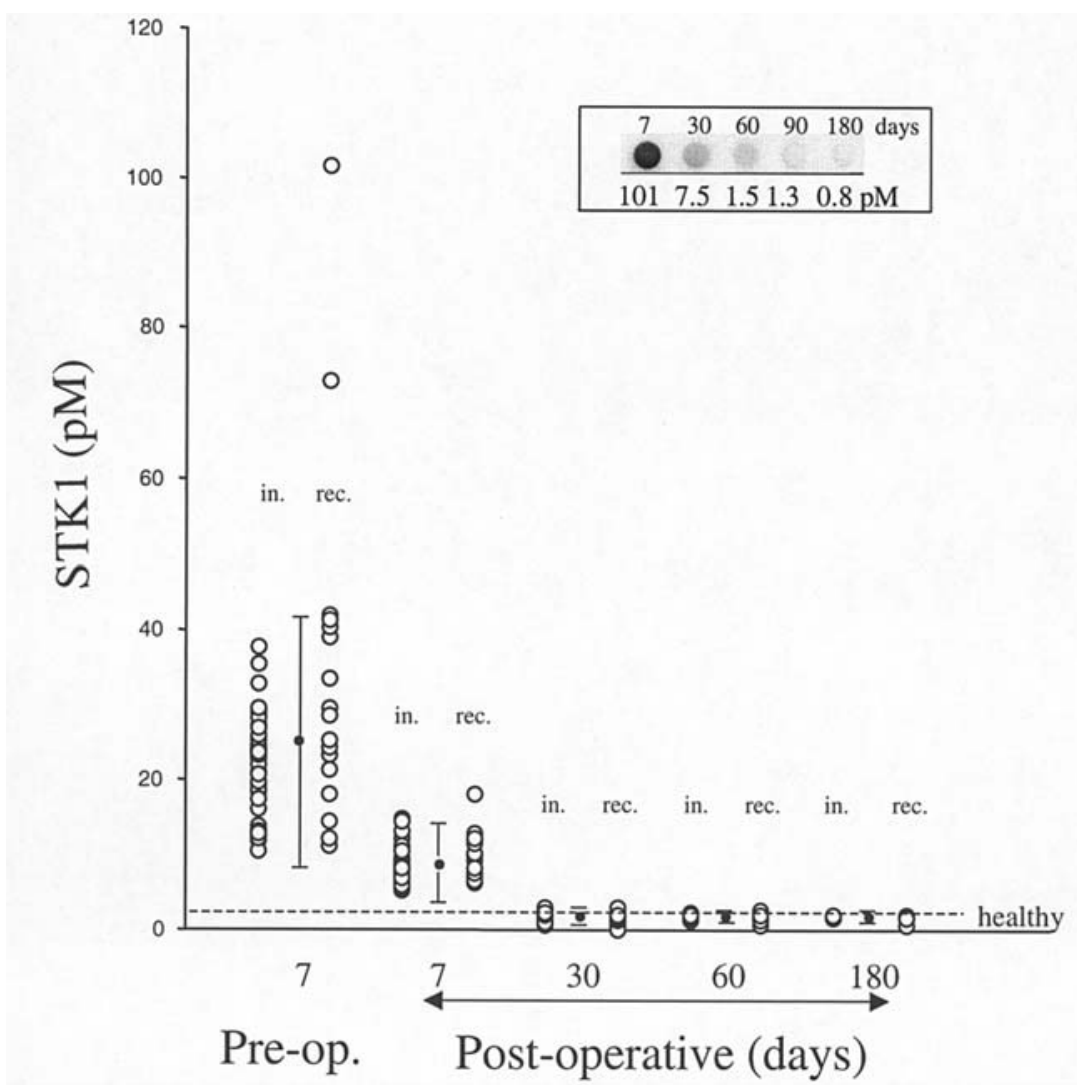

Figure 2. STK1 concentrations at 7 days pre-operatively and at 7, 30, 90, and 180 days post-operatively for individual patients (open ring) and mean values (closed circle) are indicated. The mean \pm SD values were calculated from the initial and recurrence patients together. In, initial diseases; re, recurrence. Inset, demonstration of the immune-dot blot assay showing a patient with recurrence.

grade 3 (G3) tumors was also twice that found in G1 and G2 tumors (24). The present study examines for the first time the use of TK1 concentration, rather than activity, in the serum of patients with primary bladder carcinoma as a diagnostic marker and to monitor surgical outcome.

\section{Patients and methods}

Patients. A total of 56 patients with histologically diagnosed primary bladder carcinoma ( 35 male and 21 female; median age, 52 years; range 31-84) were recruited. Informed consent was obtained, and patients were prospectively evaluated at the RenMin Hospital, Wuhan University, China, from 2000 to 2005 . Of the patients, 38 presented initial disease and 18 presented recurrence (operated once, but tumor recurred) and were assessed according to TURBt or cystectomy. According to the AJCC TNM classification system (25), the patients (initial and recurrence) could be classified as: clinical $\mathrm{T}$ value of T1 $(n=15)$, T2a $(n=14)$, T2b $(n=17)$, T3 $(n=7)$, and T4 $(n=3)$; clinical stage I $(n=17)$, stage II $(n=29)$, and stage III $(n=10)$; and tumor grades $(\mathrm{G})$ of $\mathrm{G} 1(\mathrm{n}=18), \mathrm{G} 2(\mathrm{n}=24)$, and G3 $(n=14)$. No T4 or grade 1 patients were found in the initial disease group. The clinical stage and $G$ grade classifications of the recurrence patients were done based on the recurrent tumors. Age-matched healthy persons $[n=20 ; 13$ male and 7 female; median age, 50 years (range, $31-81$ years)] were used as positive controls. No significant differences in STK1 concentration were found between different ages and gender of the healthy controls.
Serum samples were taken from all pre-operative patients 7 days before surgery. From the 56 patients who had undergone curative bladderectomy and were regarded as tumor-free, serum samples were taken 7 and 30 days post-operatively. Serum samples were further collected from 11 cases 90 days postoperatively and from 6 cases 180 days post-operatively. Sera from 20 healthy subjects were used as controls. All serum samples were collected in non-heparinized tubes in the morning after a fast of approximately $12 \mathrm{~h}$, then stored at $-20^{\circ} \mathrm{C}$ before analysis. The study was conducted in accordance with the Helsinki Declaration of 1983.

ECL dot blot analysis of STK1 concentration. STK1 concentration was measured using an enhanced chemiluminescent (ECL) dot blot assay, as previously described (21). Serum (3 $\mu \mathrm{l})$ was applied to a nitrocellulose membrane (Hyband ${ }^{\mathrm{TM}} \odot$; Amersham Pharmacia, Sweden) in duplicate. The sera were probed both with and without anti-TK1 chicken IgY antibody raised against a synthetic peptide (residue 195-225, GQP A G P D N K E N C P V P G K P GE A V A A R K L F A P Q) corresponding to part of the C-terminus of human TK1 (15), with the latter as negative controls. Recombinant human TK1 (rHTK1) was used as positive control. The membrane was blocked in TBS buffer with $10 \%$ non-fat milk for $4 \mathrm{~h}$, primary anti-TK1 IgY Ab was added, and the membrane was incubated at room temperature for $4 \mathrm{~h}$. After incubation with a biotinylated secondary antibody for $1 \mathrm{~h}$ at room temperature, the membrane was immersed in TBS buffer containing 3\% $\mathrm{H}_{2} \mathrm{O}_{2}$ for $5 \mathrm{~min}$. The membrane was then incubated in TBS 
Table II. STK1 concentrations in patients with initial disease and recurrence, separately and together (initial + recurrence) in relation to pre-operative tumor stage and grade.

\begin{tabular}{|c|c|c|c|c|c|c|}
\hline & \multicolumn{2}{|c|}{ Initial } & \multicolumn{2}{|c|}{ Recurrence } & \multicolumn{2}{|c|}{ Initial + recurrence } \\
\hline & STK1 (pM) & p-value & STK1 (pM) & p-value & STK1 (pM) & $\mathrm{p}$-value \\
\hline \multicolumn{7}{|c|}{ T-value } \\
\hline \multirow[t]{2}{*}{$\mathrm{T} 1$} & $13.7 \pm 3.0(n=13)$ & & $11.1 \pm 0.8(n=2)$ & & $13.6 \pm 3.1(n=15)$ & \\
\hline & & 0.005 & & 0.011 & & $<0.001$ \\
\hline \multirow[t]{2}{*}{$\mathrm{T} 2 \mathrm{a}$} & $20.9 \pm 5.1(n=11)$ & & $18.1 \pm 4.5(n=3)$ & & $20.3 \pm 4.9(n=14)$ & \\
\hline & & 0.004 & & $<0.001$ & & 0.002 \\
\hline \multirow[t]{2}{*}{$\mathrm{T} 2 \mathrm{~b}$} & $26.3 \pm 4.9(n=12)$ & & $29.3 \pm 5.6(n=5)$ & & $28.3 \pm 5.2(n=17)$ & \\
\hline & & 0.004 & & 0.688 & & 0.244 \\
\hline \multirow[t]{2}{*}{ T3 } & $32.8 \pm 0.0(n=2)$ & & $40.2 \pm 10.8(n=5)$ & & $32.8 \pm 8.8(n=7)$ & \\
\hline & & & & 0.269 & & 0.269 \\
\hline $\mathrm{T} 4$ & np & & $72.8 \pm 38.5(n=3)$ & & $72.8 \pm 38.5(n=3)$ & \\
\hline \multicolumn{7}{|l|}{ Stage } \\
\hline \multirow[t]{2}{*}{ I } & $13.7 \pm 4.5(n=13)$ & & $11.7 \pm 0.8(n=2)$ & & $13.6 \pm 4.4(n=15)$ & \\
\hline & & $<0.001$ & & $<0.001$ & & $<0.001$ \\
\hline \multirow[t]{2}{*}{ II } & $24.6 \pm 5.7(n=23)$ & & $26.3 \pm 8.0(n=8)$ & & $24.6 \pm 6.3(n=31)$ & \\
\hline & & $<0.001$ & & $<0.001$ & & 0.052 \\
\hline III & $32.8 \pm 0.0(n=2)$ & & $40.7 \pm 28.1(n=8)$ & & $36.5 \pm 25.4(n=10)$ & \\
\hline \multicolumn{7}{|c|}{ Grade } \\
\hline \multirow[t]{2}{*}{ G1 } & $21.4 \pm 8.0(n=18)$ & & np & & $21.4 \pm 8.0(n=18)$ & \\
\hline & & 0.814 & & & & 0.458 \\
\hline \multirow[t]{2}{*}{ G2 } & $20.7 \pm 6.8(n=13)$ & & $28.5 \pm 17.0(n=11)$ & & $21.7 \pm 13.2(n=24)$ & \\
\hline & & 0.846 & & 0.575 & & 0.519 \\
\hline G3 & $23.7 \pm 6.2(n=7)$ & & $25.3 \pm 30.1 \quad(n=7)$ & & $24.5 \pm 22.6(n=14)$ & \\
\hline
\end{tabular}

Mean values \pm SD. p-values were calculated using the Student's t-test. np, no patients.

buffer containing streptavidin-HRP and exposed to X-ray film. The intensity of spots on the film was determined using a laser densitometer (Bio-Rad Laboratories, Inc., Hercules, CA, USA). From the intensity of the rHTK1 of known concentrations $(0,1.5,4.5,13.5$, and $40.5 \mathrm{pM})$, the intensities of STK1 were recalculated and expressed as pM.

Statistical methods. The differences between the STK1 concentrations of various groups of patients and the change in STK1 concentrations of patients during the 6 months after surgery were analyzed using the Student's t-test. p-values $<0.05$ were considered statistically significant.

\section{Results}

STK1 concentration of pre-operative patients and healthy individuals.

STK1 of healthy individuals and patients. The individual and mean STK1 concentrations are shown in Table I and Figs. 1 and 2. The STK1 concentrations of healthy individuals ranged from undetectable to $2.3 \mathrm{pM}$, with a mean value of $1.2 \pm 0.6$ pM. The pre-operative STK1 concentrations of both the initial disease and recurrence ranged from 10 to $100 \mathrm{pM}$, with a mean value of $26.1 \pm 16.6 \mathrm{pM}$, statistically significantly different from that of the healthy individuals.
STK1 of patients with initial, recurrence, invasive or superficial tumors. The STK1 concentrations of pre-operative patients with recurrence were $155 \%$ higher $(33.3 \pm 14.4 \mathrm{pM})$ than those of the pre-operative patients with initial disease $(21.5 \pm 8.0 \mathrm{pM})$, a statistically significant difference (Table I). However, there was a marked overlap between the two groups (Fig. 2).

The STK1 concentrations of patients with invasive tumors $(29.6 \pm 16.0 \mathrm{pM})$ were significantly higher than those of patients with superficial tumors $(15.4 \pm 4.5 \mathrm{pM})(\mathrm{p}<0.001)$ (Table I).

STK1 in relation to tumor stage and grade. STK1 concentrations of the pre-operative patients were also related to tumor stage and grade. The individual and mean STK1 values of the initial disease and recurrence patients are presented in Table II and Figs. 1 and 2. Few initial tumor cases were $\mathrm{T} 3 / \mathrm{T} 4$ or stage 3 , while few recurrence tumors were found among $\mathrm{T} 1$ and stage I cases, indicating the aggressiveness of recurrence tumors. STK1 concentrations increased significantly by $\mathrm{T}$-value and stage, but not by grade. In patients with initial disease, STK1 concentrations were significantly different between $\mathrm{T} 1$ and $\mathrm{T} 2 \mathrm{a}, \mathrm{T} 2 \mathrm{a}$ and $\mathrm{T} 2 \mathrm{~b}, \mathrm{~T} 2 \mathrm{~b}$ and T3 cases, and stage I and II, and stage II and III cases (Table II). This was also found in the recurrence patients, except for $\mathrm{T} 2 \mathrm{~b}$ and $\mathrm{T} 3$ patients, among whom no significant difference was detected. It is important to note 
that there was no overlap of individual STK1 values for the $\mathrm{T} 1$ and $\mathrm{T} 2 \mathrm{~b} / \mathrm{T} 3 / \mathrm{T} 4$ cases, stage I and stage III cases, or patients and healthy persons (Fig. 1), demonstrating the sensitivity of this assay.

Post-operative STK1 concentrations. Changes in individual and mean STK1 concentration values following surgery are summarized in Fig. 2. All patients were regarded as tumorfree as a result of the operation. STK1 concentrations of the initial and recurrence patients decreased significantly to about 8-10 pM at 7 days after surgery, corresponding to a half-life of about 6 days. The STK1 concentrations decreased further, reaching levels corresponding to those of healthy persons at 30 days post-operatively. Eleven patients were followed up at 90 days and another 6 patients at 180 days post-operatively. STK1 concentrations of these patients were stable and remained at levels characteristic of healthy persons until 180 days post-operatively.

\section{Discussion}

Bladder cancer is among the most common malignancies in China, and occurs more frequently in males. A high frequency of recurrence is found in post-operative patients. Cytoscope examination can be done regularly to look for tumor recurrence, but this procedure causes considerable physical and psychological suffering. Much research has been devoted to finding serum biomarkers of early stage tumors; the results, however, have been limited and controversial.

One way of tumor stage detection is to determine the proliferation rate. The proportion of DNA-synthesizing cells (S-phase cells) in tumors has been used as a measure of cancer cell proliferation by means of radio-labeled thymidine in autoradiography. Incorporation of halogen-analogies of thymidine (BrdU) and antibodies against these has also been used together with quantitative flow cytometric DNA measurements. The disadvantage of using flow cytometric DNA measurements is that the technique is unable to distinguish between proliferating and non-proliferating cells. Determination of S-phase cells is even more complicated in tumors, which do not deviate in terms of DNA-content from benign cells $(26,27)$. Instead of measuring DNA-synthesis itself by the incorporation of DNA precursors, markers related to DNA synthesizing (proliferating) cells have been used to histochemically stain tissue sections, i.e Ki-67 and PCNA (proliferating cell nuclear antigen) $(28,29)$.

Thymidine kinase (TK), an enzyme of the pyrimidine salvage pathway, catalyzes the phosphorylation of thymidine to thymidine monophosphate. TK is a key enzyme involved in DNA synthesis. TK in human cells appears in two forms, a cytoplasmic (TK1) and mitochondrial (TK2) protein, encoded by different genes. Human TK1 and TK2 are located on chromosomes 17q23.2-q25.3 (30) and 16q22-q23.1 (31) respectively. The expression of TK1 is cell-cycle regulated, and TK1 regulation is complex with mRNA levels peaking in $\mathrm{S}$-phase cells. TK1 levels are mainly regulated by posttranslational mechanisms, particularly by differential degradation due to highly active protease expression in mitotic cells. TK 2 activity is about $5 \%$ of that of TK1 and only found in resting cells. TK2 is not cell-cycle regulated (32-34). The C-terminal region of TK1 contains a specific sequence, KEN, which has been shown to be a signal of the mitotic degradation of TK1 by the anaphase-promoting complex/cyclosome-cdh1-mediated pathway (35). This crucial cell cycle regulated ubiquitin-proteasome pathway present in mammalian cells is responsible for the degradation of several other key proteins, such as cdc20, cdc25A, and ribonucleotide reductase (35).

TK has been used to identify proliferating cells in cancer tissues. Using thymidine or its analogue 5-iodo-2'-deoxyuridine as a substrate, TK activity in serum (STK) was established as a proliferation marker in 1980 (36). Previous results indicate that STK1 is a polymeric form of TK1, probably existing in complex with other serum proteins, and has a total molecular weight of approximately $700 \mathrm{kDa}$ (37). The STK activity is useful for the estimation of tumor spread and prognosis in patients with leukemia (38), Hodgkin and non-Hodgkin's lymphoma (36) or preoperative patients with advanced ovarian cancer (39), but not for prognosis and monitoring the outcome of tumor therapy in solid tumors (22). TK activity was also determined in cytosol fractions of breast tumor tissues of 1,692 patients. High TK1 activity correlated to a shorter survival, as well as poor outcome of chemotherapy and endocrine treatment (tamoxifen) (23). Cytosolic TK activity also correlated with tumor stage and grade in primary bladder carcinomas (24).

Anti-TK1 antibodies have been developed for potential clinical purpose in both serological and histochemical detection $(15,19,34)$. We have developed an anti-TK1 chicken IgY antibody, raised against a 31 synthetic peptide corresponding to the C-terminus of human TK1 (15). This part of the TK1 polypeptide is involved in the cell-cycle regulation of TK1 synthesis (34) and its mitotic degradation by the anaphasepromoting complex/cyclosome-Cdh1-mediated pathway (35).

The present study is the first to explore the use of STK1 concentration as a prognostic factor and to monitor the outcome of surgery in primary bladder carcinoma patients. We found that the mean concentration of STK1 of bladder carcinoma patients before surgery, including patients with initial and recurrence tumors, was significantly higher $(\mathrm{p}<0.001)$ than that of healthy individuals. We also found a close correlation between increasing STK1 concentrations and stages, similar to the results on cytosolic TK1 activity in bladder carcinomas (24). In that study, however, there was an extensive overlap in TK1 activity between healthy and malignant patients and between the various stages and grades, which may limit the use of cytosolic TK1 activities on an individual patient basis (24). In the present study on STK1 concentration, we did not observe any overlap between healthy and malignant patients or T1 and T3/T4 and almost no overlap between stages 1 and 3 , indicating that the determination of STK1 concentration is more reliable than cytosolic TK1 activity. The reason could be that the STK enzyme activity is highly sensitive to temperature and $\mathrm{pH}$ changes, especially when determining TK activity at low levels. On the other hand, the cytosolic TK1 activity of tumors correlated positively to grade, while TK1 concentration in serum in our study did not.

The high concentration of STK1 in the recurrence and invasive patient groups, as well as higher STK1 concentrations in patients with higher tumor T-values and stages, confirmed 
that STK1 concentration is a reliable marker for proliferation in malignant patients. It is also of note that STK1 concentration was able to distinguish between the superficial and invasive type of tumors, which TPA is unable to do (4).

The most significant results of this study are the close correlation of STK1 concentration to the outcome of surgery. Of those patients who were regarded as tumor-free due to surgery, the STK1 concentrations decreased by about $65 \%$ after 1 week and reached the STK1 value of healthy persons after 1 month and remained at this level up to 6 months. There was no overlap in STK1 concentrations between preoperative patients and patients at 1 month after surgery, showing that STK1 concentration is a useful marker for monitoring the outcome of surgery on an individual patient basis. Similar results were found in patients with gastric (22), breast (21) and lung (40) cancer, when STK1 concentrations were used to follow the results of surgery. In these cases, however, the half-life of STK1 was about 1 month compared to $<1$ week in patients with bladder carcinoma. One reason for this discrepancy could be that in cases of gastric, breast and lung cancer, there are few but a significant number of malignant cells either left after surgery or as metastasis, contributing to the level of STK1, while this is not the case in primary bladder carcinoma. Although the composition and properties of STK1 are not yet well understood, it is obvious that STK1 is useful as a potential marker for evaluating the effectiveness of treatment, not only in patients with bladder cancer, but also in other types of malignant diseases.

In conclusion, since STK1 concentration correlates both to tumor stage, tumor size (T1 and T2) and degree of invasion, and monitors the results of surgery, STK1 can be used as a reliable index to diagnose and foretell the prognosis in bladder cancer patients post-operatively.

\section{Acknowledgements}

This investigation was supported by grants from the faculty of Karolinska Institute, Stockholm, and Clinical Research Center, Karolinska University Hospital, Huddinge, Sweden. We also thank Sino-Swed Ting Kang Biological Technology Inc., Shenzhen, China, for the generous gift of anti-TK1 chicken IgY antibody, and Professor Staffan Eriksson, Department of Molecular Biosciences, Section of Veterinary Medical Chemistry, Swedish University of Agricultural Science, Sweden, for the generous gift of purified recombinant human TK1 (rHTK1).

\section{References}

1. Cook AM, Huddart RA, Jay G, Norman A, Dearnaley DP and Horwich A: The utility of tumor markers in assessing the response to chemotherapy in advanced bladder cancer. Br J Cancer 82: 1952-1957, 2000.

2. Izes JK, Dyer MW, Callum MG, Bankes P, Libertino JA and Caffrey JA: Ca 125 as a marker of tumor activity in advanced urothelial malignancy. J Urol 165: 190-193, 2001.

3. Moreno Sierra J, Maestro de las Casas ML, Ortega Heredia MD, Blanco Jimenez E, Hermida Gutierrez J and Resel Estevez L: Serum and tissue quantification of tissue polypeptide antigen (TPA) in transitional cell carcinoma of the bladder. Arch Esp Urol 47: 979-984, 1997.

4. Ecke TH, Lenk SV, Schlechte HH and Loening SA: Tissue polypeptide antigen (TPA) in comparison with mutations of tumour suppressor gene P53 (TP53) in patients with bladder cancer. Anticancer Res 23: 957-962, 2003.
5. Sanchez-Carbayo M, Espasa A, Chinchilla V, Herrero E, Megias J, Mira A and Soria F: New electrochemiluminescent immunoassay for the determination of CYFRA 21-1: analytical evaluation and clinical diagnostic performance in urine samples of patients with bladder cancer. Clin Chem 45: 1944-1953, 1999.

6. Pariente JL, Bordenave L, Jacob F, Gobinet A, Leger F, Ferriere JM and Le Guillou M: Analytical and prospective evaluation of urinary cytokeratin 19 fragment in bladder cancer. J Urol 163: 1116-1119, 2000.

7. Menendez V, Galan JA, Fernandez-Suarez A, Lopez S, Alcover J, Calpena R and Filella X: Prognostic value of tissue-polypeptide specific antigen (TPS) in bladder cancer. Anticancer Res 22: 3713-3716, 2002.

8. Ramazan Sekeroglu M, Aydin S, Dulger H, Yilmaz Y, Bayrakli H and Noyan T: Diagnostic value of cytokeratin-18 as a tumor marker in bladder cancer. Clin Biochem 35: 327-331, 2002.

9. Mady EA: Cytokeratins as serum markers in Egyptian bladder cancer. A comparison of CYFRA 21-1, TPA and TPS. Int J Biol Markers 16: 130-135, 2001

10. Kelloniemi E, Rintala E, Finne P, Stenman UH and Finn Bladder Group: Tumor-associated trypsin inhibitor as a prognostic factor during follow-up of bladder cancer. Urology 62: 249-253, 2003.

11. Simms MS, Hughes OD, Limb M, Price MR and Bishop MC: MUC1 mucin as a tumor marker in bladder cancer. BJU Int 84: 350-352, 1999.

12. Sanchez-Carbayo M: Use of high-throughput DNA microarrays to identify biomarkers for bladder cancer. Clin Chem 49: 23-31, 2003.

13. Valenzuela MT, Galisteo R, Zuluaga A, Villalobos M, Nunez MI, Oliver FJ and Ruiz de Almodovar JM: Assessing the use of p16(INK4a) promoter gene methylation in serum for detection of bladder cancer. Eur Urol 42: 622-628, 2002.

14. Mao YR, Wu JP, Wang N, He JX, Wu CJ, He Q and Skog S: Comparison study: immunohistochemical detection of cytosolic thymidine kinase and proliferating cell nuclear antigen in breast cancer. Cancer Inv 20: 922-931, 2002.

15. Wu CJ, Yang RJ, Zhou J, Bao S, Zou L, Mao YR and He Q: Production and characterisation of a novel chicken IgY antibody raised against C-terminal peptide from human thymidine kinase 1 . J Immunol Method 277: 157-169, 2003.

16. He Q, Mao RY and Wu JP: Immunohistochemical expression of thymidine kinase in patients with breast carcinoma. In: Immunohistochemical and In Situ Hybridisation of Human Carcinomas. Hayat MA (ed). Elsevier Science/Academic, San Diego, CA, pp463-470, 2004.

17. He Q, Mao YR, Wu JP, Decker C, Merza M, Wang N, Eriksson S, Castro J and Skog S: Cytosolic thymidine kinase is a specific histopathologic tumour marker for breast carcinomas. Int J Oncol 25: 945-953, 2004.

18. Mao YR, Wang N, Wu JP, Hu LX, Wu CJ, He Q and Skog S: A new cell proliferating marker: cytosolic thymidine kinase as compared to proliferating cell nuclear antigen in patients with colorectal carcinoma. Anticancer Res 20: 4815-4820, 2001.

19. Kuroiwa N, Nakayama M, Fukuda T, Fukui H, Ohwada H, Hiwasa $T$ and Fujimura S: Specific recognition of cytosolic thymidine kinase in the human lung tumor by monoclonal antibody raised against recombinant human thymidine kinase, $\mathrm{J}$ Immunol Methods 253: 1-11, 2001.

20. Wang N, He Q, Skog S, Eriksson S and Tribukait B: Investigation on cell proliferation with a new antibody against thymidine kinase 1. Anal Cell Pathol 23: 11-19, 2001.

21. He Q, Zou L, Zhang P, Liu J, Skog S and Fonander T: The clinical significance of thymidine kinase 1 measurement in serum of breast cancer patients using anti-TK1 antibody, Int J Biol Markers 15: 139-146, 2000.

22. Zou L, Zhang PG, Zou S, Li Y and He Q: The half-life of thymidine kinase 1 in serum measured by ECL dot blot: a potential marker for monitoring the response to surgery of patients with gastric cancer. Int J Biol Markers 17: 135-140, 2002.

23. Broet P, Romain S, Daver A, Ricolleau G, Quillen V, Rallet A, Asselain B, Martin PM and Spyratos F: Thymidine kinase as a proliferative marker: Clinical relevance in 1,692 primary breast cancer patients. J Clin Oncol 19: 2778-2787, 2001.

24. Mizutani Y, Wada H, Yoshida O, Fukushima M, Kamoi K and Miki T: Prognostic significance of thymidine kinase activity in bladder carcinoma. Cancer 95: 2120-2125, 2002. 
25. Greene FL, Page DL, Fleming ID, Fritz AG, Balch CM, Haller DG and Morrow M: AJCC cancer stage. Manual. 5th edition. Springer, New York, pp167-178, 1997.

26. Wilson GD: Assessment of human tumour proliferation using bromodeoxyuridine - current status. Acta Oncol 30: 903-910, 1991.

27. Tribukait B: Flow cytometry in assessing the clinical aggressiveness of genito-urinary neoplasms. World J Urol 5: 108-122, 1987.

28. Hall PA and Woods AL: Immunohistochemical markers of cellular proliferation: achievements, problems and prospects. Cell Tissue Kinet 25: 505-522, 1990.

29. Scholzen T and Gerdes J: The Ki-67 protein: from the known and the unknown. J Cell Physiol 182: 311-322, 2002.

30. Elsevier SM, Kucherlapati RS, Nichols EA, Creagan RP, Giles RE, Ruddle FH, Willecke K and McDougall JK: Assignment of the gene for galactokinase to human chromosome 17 and its regional localization to band q21-22. Nature 251: 633-636, 1974.

31. Willecke K, Teber T, Kucherlapati RS and Ruddle FH: Human mitochondrial thymidine kinase is coded for by a gene on chromosome 16 of the nucleus. Somatic Cell Genet 3: 237-245, 1977.

32. Munch-Petersen B, Cloos L, Jensen HK and Tyrsted G: Human thymidine kinase 1 . Regulation in normal and malignant cells. Adv Enzyme Regul 35: 69-89, 1995.

33. Eriksson S, Munch-Petersen B, Johansson K and Eklund $\mathrm{H}$ : Structure and function of cellular deoxyribonucleoside kinases. Cell Mol Life Sci 59: 1327-1346, 2002.
34. He Q, Skog S, Wang N, Eriksson S and Tribukait B: Characterization of a peptide antibody against a C-terminal part of human and mouse cytosolic thymidine kinase, which is a marker for cell proliferation. Eur J Cell Biol 70: 117-124, 1996.

35. Ke PY and Chang ZF: Mitotic degradation of human thymidine kinase 1 is dependent on the anaphase-promoting complex/ cyclosome-CDH1-mediated pathway. Mol Cell Biol 24: 514-526, 2004.

36. Gronowich JS, Hagberg H, Källander CFR and Simonsson B: The use of serum deoxythymidine kinase as a prognostic marker, and in the monitoring of patients with non-Hodgkin's lymphoma. Br J Cancer 47: 487-495, 1983.

37. Karlström AR, Neumuller M, Gronowitz JS and Kallander CF: Molecular forms in human serum of enzymes synthesizing DNA precursors and DNA. Mol Cell Biochem 92: 23-35, 1990.

38. Fujiwara H, Arima N, Ohtsubo H, Matsumoto T, Kukita T, Kawada H, Imaizumi R, Ozaki A, Matsushita K and Tei C: Clinical significance of serum neuron-specific enolase in patients with adult T-cell leukemia. Am J Hematol 71: 80-84, 2002.

39. Hallek M, Touitou Y, Levi F, Mechkouri M, Bogdan A, Bailleul F, Senekowitsch R and Emmerich B: Serum thymidine kinase levels are elevated and exhibit diurnal variations in patients with advanced ovarian cancer. Clin Chim Acta 267: 155-166, 1997.

40. Li HX, Zhang S, Lei DS, Wang XQ, Skog S and He Q: Serum thymidine kinase 1 (STK1) is a prognostic and monitoring factor in patients with non-small-cell lung cancer. Oncol Rep 13: 145-149, 2005. 